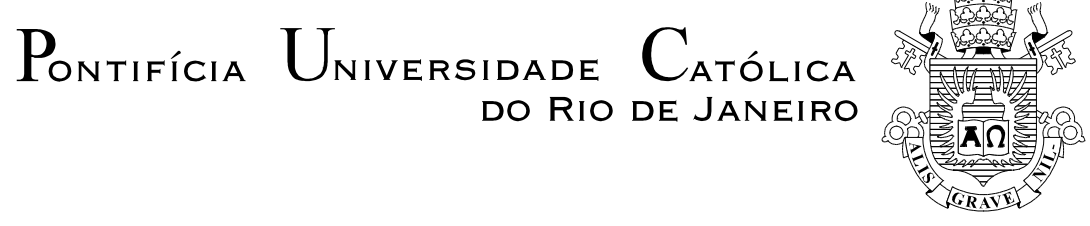

Roberta Portas Gonçalves Rodrigues

Projeto de conclusão de curso de design -
Comunicação Visual: um estudo de caso

Dissertação de Mestrado

Dissertação de mestrado apresentada ao programa de pós-graduação em Design da PUC-Rio como requisito parcial para obtenção do título de Mestre em Design.

Profa. Dra Rita Maria de Souza Couto Orientador 


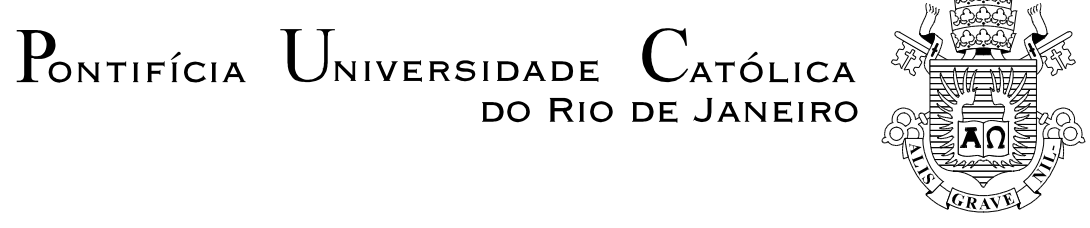

Roberta Portas Gonçalves Rodrigues

\title{
Projeto de conclusão de curso de design - Comunicação Visual: um estudo de caso
}

\section{Dissertação de Mestrado}

Dissertação de mestrado apresentada ao programa de pós-graduação em Design da PUC-Rio como requisito parcial para obtenção do título de Mestre em Design. Aprovada pela Comissão Examinadora abaixo assinada.

\author{
Rita Maria de Souza Couto \\ Orientador \\ Departamento de Artes \& Design - PUC-Rio
}

\section{Flávia Nízia da Fonseca Ribeiro} UNIRIO

Luiza Novaes

Departamento de Artes \& Design - PUC-Rio

Prof. Paulo Fernando Carneiro de Andrade

Coordenador Setorial do Centro de Teologia e Ciências Humanas - PUC-Rio 
Todos os direitos reservados. É proibida a reprodução total ou parcial do trabalho sem autorização da universidade, da autora e do orientador.

\section{Roberta Portas Gonçalves Rodrigues}

Graduou-se em Desenho Industrial, com habilitação em Comunicação Visual, na Faculdade da Cidade - Rio de Janeiro em 1994. É professora do quadro complementar do Departamento de Artes e Design da PUC-Rio desde 2009.

Ficha catalográfica

Rodrigues, Roberta Portas Gonçalves

Projeto de conclusão de curso em design - comunicação visual: um estudo de caso / Roberta Portas Gonçalves Rodrigues ; orientador: Rita Maria de Souza Couto. - 2009 100 f. : il.(col.) ; $30 \mathrm{~cm}$

Dissertação (Mestrado em Design)-Pontifícia Universidade Católica do Rio de Janeiro, Rio de Janeiro, 2009. Inclui bibliografia

I. Artes - Teses. 2. Comunicação visual. 3. Desenvolvimento de projeto. 4. Processo de projeto em Design. 5. Processos de criação. I. Couto, Rita Maria de Souza. II. Pontifícia Universidade Católica do Rio de Janeiro. Departamento de Artes \& Design. III. Título.

CDD: 700 
Para Karla e Glória, meu carinho especial.

In Memorian Airton Caminha Gonçalves, Sylvio Portas Gonçalves, Delon, Dora, Nina, Luar e Delfin. 


\section{Agradecimentos}

A minha família que sempre me apoiou nas minhas escolhas, especialmente minha mãe Lucia Beatriz e meus irmãos Manuela e Jaiminho.

A Capes e a PUC-Rio pelos auxílios concedidos, sem aos quais este trabalho não poderia ter sido realizado.

A minha Orientadora Rita Couto que foi um presente de Deus.

A Professora Izabel de Oliveira pelo seu carinho, apoio, suporte, disponibilidade, generosidade e outros tantos adjetivos que são poucos para resumir toda acolhida que me foi dada.

Ao Professor Celso Wilmer por suagenerosidade e empenho nas leituras e conhecimento compartilhado. Devo muito a você.

As professoras Luiza Novaes e Flávia Nizia da Fonseca Ribeiro por aceitarem o convite de compor a banca e colaborarem com seus comentários para o enriquecimento desta pesquisa.

Aos professores e alunos da disciplina Planejamento, Projeto e Desenvolvimento, Comunicação Visual Conclusão (PPD-CV Conclusão), João Lobato, Kelly Andreolli e Ana Baldan.

Aos Professores da Pós-graduação da PUC-Rio em especial: Denise Portinari, Gamba Jr, Claudia Mont'Alvão, Alberto Cipiniuk, Maria Apparecida Mamede e Eliana Yunes.

Aos meus colegas de mestrado, Miguel e Luiz Carlos!

Aos meus amigos que acompanharam esta jornada e que me apoiaram nos dias que não pude estar presente as comemorações, em especial Laura Di Pietro, Ana Cartaxo, Gláucio, Lili, Paulo Góes, Andrea Carestiato, Pepê, Gabriela Queiroz, Joy Till, Cris Veneu, Flávia Toledo e Gabriela Maciel.

Aos demais amigos e familiares que não estão citados (a lista seria enorme), mas que de uma forma ou de outra sempre me estimularam.

Obrigada! 


\section{Resumo}

Portas, Roberta G. R.; Couto, Rita Maria de Souza. Projeto de Conclusão de Curso de Design - Comunicação Visual: um estudo de caso. Rio de Janeiro, 2009. 100p. Dissertação de Mestrado - Departamento de Artes \& Design, Pontifícia Universidade Católica do Rio de Janeiro.

Observar o desenvolvimento de projetos de alunos em Design é um ótimo exercício na busca afinarmos as diretrizes de uma instituição de ensino com o real processo percorrido pelos alunos. A presente pesquisa é um estudo de caso realizado com alunos da disciplina Planejamento, Projeto e Desenvolvimento Comuicação Visual Conclusão (PPD-CV Conclusão), última disciplina de projeto do curso de Design da PUC-Rio, habilitação Comunicação Visual, pertencente ao currículo em vigor para alunos que ingressaram por vestibular até 2007. Durante o segundo semestre de 2007 e o primeiro semestre de 2008, o desenvolvimento dos projetos dos alunos da turma da professora tutora lzabel de Oliveira foi observado com o objetivo de identificar nas etapas percorridas pelos alunos, lacunas que pudessem ser trabalhadas. No processo destacamos 4 projetos que são apresentados à luz de fundamentação teórica, trazendo um olhar crítico sobre os processos percorridos pelos alunos.

\section{Palavras-chave}

Comunicação visual; desenvolvimento de projeto; processo de projeto em Design; processos de criação. 


\section{Abstract}

Portas, Roberta G. R.; Couto, Rita Maria de Souza (Advisor). Design Course Completion Project - Visual Communication: A Case Study. Rio de Janeiro, 2009. 100p. MSc. Dissertation - Departamento de Artes \& Design, Pontifícia Universidade Católica do Rio de Janeiro.

The development of projects by Design students is an excellent exercise when it comes to searching for the gaps to be covered in an attempt to finetune the guidelines of a teaching institution based on the real progress made by its students. This research involves a case study conducted with students of the PPD-CV Conclusion Course, the last subject in the Design course at PUC-Rio, Visual Communications Major, belonging to the curriculum prior to 2007. During the second semester of 2007 and the first semester of 2008, the researchers observed the development of the projects by students from the class of Tutor Professor Izabel de Oliveira with the objective of identifying the stages completed by the same as they develop their projects, gaps that could be worked. In order to ensure a critical perspective on the completed processes, the researchers highlight four projects that are presented based on a theoretical foundation.

\section{Keywords}

Visual communication; project development; Design project process, creative processes. 


\section{Sumário}

I. Introdução

2. PPD-CV Conclusão 2007.2 e 2008. I

2.I Etapas do PPD-CV Conclusão 20

2.2 Aula inaugural $\quad 22$

2.3 Aulas iniciais $\quad 22$

2.4 Entrega de propostas $\quad 23$

2.5 Avaliação de pertinência das propostas 24

2.6 Início do processo de orientação 25

$\begin{array}{ll}2.7 \text { Os principais momentos da disciplina } & 27\end{array}$

2.7.I Proposta 27

$\begin{array}{ll}2.7 .2 \text { Pré-banca } & 28\end{array}$

2.6.3 Banca Final $\quad 30$

2.8 Percurso do aluno na disciplina 31

3. Projetos selecionados à luz da fundamentação teórica 32

3.I O sujeito e suas relações 33

3.2 Projetos selecionados 4I

3.2.I Paraíso - Festa Trance - João Lobato 4I

3.2.2 Entre Quatro Paredes - Kelly Andreolli 63

3.3 Projetos desenvolvidos em um semestre $\quad 75$

3.3.I Projeto Fluminense $\quad 75$

3.3.I Projeto Revista de Cultura $\quad 78$

3.3 Conclusão parcial $\quad 82$

4. Considerações Finais $\quad 83$

4.I Resultados da Pesquisa de campo 83

$\begin{array}{ll}4.2 \text { Para finalizar } & 87\end{array}$

$\begin{array}{ll}\text { Referências Bibliográficas } & 89\end{array}$

$\begin{array}{ll}\text { Anexos } & 90\end{array}$ 


\section{Lista de figuras}

$\begin{array}{ll}\text { Figura I - Mapeamento do recorte da pesquisa. } & 13\end{array}$

Figura 2 - Mapeamento do ambiente profissional onde o designer $\quad 14$

está inserido.

Figura 3 - Mapeamento do ambiente acadêmico onde o designer está inserido.

Figura 4 - Diagrama das relações entre cultura, objeto e o sujeito.

Figura 5 - Diagrama da sala KI4, sala da turma da professora

Izabel Oliveira (mesa I) com a disposição das mesas dos professores tutores.

Figura 6 - Calendário apresentado aos alunos na aula inaugural e

é disponibilizado para download no site do departamento (vide anexo2).

Tabelal - Síntese dos principais momentos na disciplina para alunos de I e 2 ou mais semestres.

Figura 7 - (Winnicott, 1975; p. 27). Esquema feito pelo autor para ilustrar a sobreposição dos campos e localizar a substância da ilusão e o objeto transicional.

Figura 8 - Diagrama das relações entre cultura, objeto e o

sujeito, localizando as duas realidades que são articuladas pelo objeto em processo de criação.

Figura 9 - Marcel Duchamp. Porte, numero I I , rue Larrey ( 927 ) http://content.cdlib.org/xtf/view?docld=ft9h4nb688\&chunk. id $=0$ \&doc.view $=$ print [capturada em 23/I I/2007]

Figura 10 - Diagrama resumo localizando o pensamento de

Winnicott, Ostrower e Schön.

Figura I I - Mapa de ocupação apresentada no relatório do aluno.

Figura 12 - llustração esquemática de ocupação da área apresentada no relatório do aluno. Nota: Brainstorm na legenda da imagem é o título do labirinto, e não de uma etapa de projeto.

Figura 13 - llustração inicial da árvore para a pista de dança desenhada no bloco A3 de papel Kraft que o aluno levava para as aulas.

Figura 14 - llustração de representação da malha de folhas com a projeção da sombra com a intenção de dar conforto aos participantes. Desenho apresentado no relatório do aluno. 
Figura 15 - llustração da árvore para a pista de dança

contemplando a estrutura e reforçando a escala de representação adotada. Desenhos apresentados no relatório do aluno.

Figura 16 - maquete esquema para criação do cérebro. Nota: A

base desta maquete é composta por 3 placas de isopor, atingindo a medida de I,5 $\times 1,0 \mathrm{~m}$.

Figura 17 - 3 estágios da árvore como objeto de projeto.

51

Figura 18 - Representação das maçãs do pecado apresentadas

no relatório do aluno.

Figura 19 - Desenho esquemático do Chillout apresentado no relatório do aluno.

Figura 20 - Desenho de representação do chuveiro de Deus.

Figura 2l - Fotografia do processo de construção do modelo do

chuveiro "Mão de Deus" feito a partir de um bloco de isopor.

Figura 22 - Fotografia do modelo de isopor esculpido.

56

Figura 23 - Detalhe do bloco do aluno com o registro das

experiências para o labirinto.

Figura 24 - Divisão inicial proposta para os 5 sentidos, com mais divisões.

Figura 25 - Divisão simplificada, favorecendo a divisão de grandes áreas de experiências sensoriais com poucas divisões internas.

Figura 26 - Esquema digital usando a maquete virtual para a distribuição das atividades no labirinto e veículo de comunicação com a equipe de colaboradores. Imagem do relatório do aluno. Figura 27 - Imagens da maquete física ( I, 2 e 3) e tela da mesma representação em 3D (4).

Figura 28 - Tela da representação em 3D do espaço relacionado ao tato na maquete virtual.

Figura 29 - Detalhe da ilustração em nanquim, desenvolvida na disciplina de Laboratório de Representação Gráfica II.

Figura 30 - Detalhe da prancha A2 com as referências de lingerie.

Apresentado no relatório de projeto.

Figura 3I - A esquerda detalhe da ilustração que foi ponto de partida para o projeto de conclusão e a direita detalhe da ilustração final apresentada para o projeto de conclusão.

Figura 32 - exemplo de aplicação de rapport na produção de estampa corrida.

Figura 33 - ilustração final que serviu como base para aplicação nas peças do cenário, a partir do desmembramento do desenho em escalas diferentes. 
Figura 34 - (I) Aro de estrutura para o soutien meia-taça e (2)

estrutura da cortina influenciada pela peça do soutien.

Figura 35 - Imagens da ficha resumo entregue pelo aluno no ato

de sua banca final de avaliação.

Figura 36 - (I) Capa da revista e (2) página I onde é apresentado

o argumento da revista e as seções de conteúdo.

Figura 37 - Página da programação musical da revista.

80

Figura 38-Dupla de páginas apresentando matéria de companhia de dança.

Figura 39 - Dupla de páginas na divisa entre duas seções, final da programação de dança e início de artes plásticas.

Figura 40 - Dupla de páginas apresentando trabalhos publicados na seção "Janela aberta".

Figura 4I - Calendário apresentado aos alunos na aula inaugural e é disponibilizado para download no site do departamento (vide anexo2).

Figura 42 - Calendário com intervenção gráfica da aluna para localizar as etapas de projeto nos momentos da disciplina, aplicada na tela de fundo do computador. (vide anexo 3 ). 